Article

\title{
Empirical Study on the Factors Affecting User Switching Behavior of Online Learning Platform Based on Push-Pull-Mooring Theory
}

\author{
Heng $X u^{1}{ }^{1}$ Jingru Wang ${ }^{1}$, Zhaodan Tai ${ }^{2,3} \mathbb{D}$ and Hao-Chiangkoong Lin ${ }^{4, *}$ \\ 1 School of Management, Henan University of Technology, Zhengzhou 450001, China; \\ xuheng@haut.edu.cn (H.X.); wjreffort@stu.haut.edu.cn (J.W.) \\ 2 School of Foreign Languages, Henan University of Technology, Zhengzhou 450001, China; \\ taizhaodan@haut.edu.cn \\ 3 Graduate School of Management, Management and Science University, Shah Alam 40100, Malaysia \\ 4 Department of Information and Learning Technology, National University of Tainan, Tainan 700, Taiwan \\ * Correspondence: koong@gm2.nutn.edu.tw
}

\section{check for}

updates

Citation: Xu, H.; Wang, J.; Tai, Z.; Lin, H.-C. Empirical Study on the Factors Affecting User Switching Behavior of Online Learning Platform Based on Push-Pull-Mooring Theory. Sustainability 2021, 13, 7087. https:// doi.org/10.3390/su13137087

Academic Editors: Antonio-Manuel Rodríguez-García, María-Natalia Campos-Soto and Juan Carlos de la Cruz-Campos

Received: 21 May 2021

Accepted: 22 June 2021

Published: 24 June 2021

Publisher's Note: MDPI stays neutral with regard to jurisdictional claims in published maps and institutional affiliations.

Copyright: (c) 2021 by the authors. Licensee MDPI, Basel, Switzerland. This article is an open access article distributed under the terms and conditions of the Creative Commons Attribution (CC BY) license (https:// creativecommons.org/licenses/by/ $4.0 /)$

\begin{abstract}
Online learning is gaining popularity, but users can easily find alternatives and switch between learning platforms. Reducing users switching behavior is a critical condition for the sustainable development of an online learning platform; therefore, it is necessary to investigate the influence factors of users switching behavior between different platforms to retain users and enhance the competitiveness of enterprises. Push-Pull-Mooring (PPM) theory is adopted to construct a structural equation model of customer switching behavior on online learning platforms and to explore the mechanism of user switching behavior between learning platforms. The model is tested with data collected from 313 online learning users. The results show that information overload and dissatisfaction, as push factors, significantly affect user switching behavior. Functional value and network externality as pull factors positively affect user switching behavior, switching cost, and affective commitment as mooring factors negatively correlate with switching behavior. Further, this study also revealed that there are obvious different influencing factors for different online learning platforms. Overall, this study provides some practical strategies for the online learning platform and can help them to gain a competitive advantage.
\end{abstract}

Keywords: online learning; user switching behavior; PPM; sustainable development

\section{Introduction}

The increasing availability of the Internet and computer technology has transformed the education mode from the traditional way to online learning. People can access information anytime and anyplace that would normally be available only through a traditional classroom [1]. Online learning applies innovative technologies and facilitates, such as smart devices and online technologies, to realize sustainability in education [2]. According to the statistical report on the development of the Internet in China, by June 2020, 381 million online learning users have accounted for $40.5 \%$ of the total Internet users. In particular, during the COVID-19 epidemic, online education customers had increased significantly due to the epidemic situation [3] and the marketing development of the online learning market. In order to occupy the market, online learning platforms mostly launch free live classes and other activities to attract customers to experience its services. IResearch data shows that the penetration rate of online learning has reached the ceiling, and the competition for the existing customer is now becoming common. Additionally, the online learning market has become more competitive and the cost of acquiring new customers is high, therefore, how to retain existing users is the key factors for the sustainable development of online learning platforms. Furthermore, the sustainable development of online learning platforms is increasingly important for sustainability in education. According to the goal 
of Agenda 2030, the sustainable development of online learning platforms would have significance for building and upgrading inclusive and effective learning environments for all and promote life-long learning opportunities for all.

Due to the continuity of course learning and the switching cost, once users choose a learning platform, they will not quickly change the learning platform in a short period [4]. However, faced with online learning platforms providing more choices, users will have different needs and may be interfered by external factors, such as the recommendations of teachers or other students' adoption. These conditions can result in users switching behaviors, indicating the loss of the existing users and the economic loss for the original platform [1]. Therefore, the online learning platform needs to explore the motivation of online learning user switching behavior and make strategic adjustments to satisfy the needs of users, attracting new users more effectively and retaining the existing users so as to obtain a competitive advantage.

The remainder of the paper proceeds as follows. The second section briefly introduces the relevant literature. Section 3 builds the research framework. Section 4 conducts a quantitative survey to test this model, and the results are provided in Section 5. Finally, this paper makes a summary of the major findings and provide some suggestion for online learning providers.

\section{Literature Review}

\subsection{User Switching Behavior}

Switching behavior is defined as consumers' choices from one provider to an alternative. It is usually associated with users' dissatisfaction with the incumbent product or service, along with their perceptions of the relative advantage of substitutes [5]. Early literature focused on user switching behaviors in many industries, like the airline industry [6], hotels [7], and Airbnbs [8]. In line with the growing prevalence of online services activities, the number of studies on the switching behavior of Information Technology (IT) products has increased in recent years [9]. The user's IT product switching behavior is somewhat different from physical products and services. First, IT innovations allow users to switch between different products with almost the same function freely since users can easily download and install other IT products. Second, IT product switch involves not only a complete replacement but also a partial replacement of the use of the former IT products or services.

IT product switching behavior is a special user's post-adoption behavior, one of the most mature streams of information system (IS) research [10]. Previous post-adoption studies focused on user's continued usage. The ultimate success of an IT product or service depends on its continued use. Facing different IT produces, users would compare them and switch from one product to a competitor. For the initial product provider, switching behavior among different alternatives indicates that the users discontinue using the previous product. Therefore, the user's switching behavior is also one stream of post-adoption behavior studies.

This switching phenomenon has been documented in various IT products, such as web browsers [11,12], cloud storage services [10,13], social networks [14], instant message application [15], and other IT services [16,17]. Through the literature review of IT user switching behavior, we found that previous studies mainly investigated switching behavior through the view of IT acceptance and diffusion [10]. Second, most previous studies focused on computer-based IT products, while few studies have focused on user switching behavior in the context of online education. Furthermore, research in the field of online learning has mainly focused on marketing and information systems [18,19], or they have focused on the influencing factors of continuous use intention [20] and paid more attention to the switch from online to offline. There is limited research on the switching behavior between online learning platforms and comprehensively identifying its antecedent factors. With the rapid growth of online learning platforms, exploring the influence mechanism of switching behaviors is of great significance to the sustainable development of online 
learning platforms. To address this gap, this paper attempts to explore the influencing user switching behavior in the context of online learning platform.

\subsection{Push-Pull-Mooring (PPM)}

We now turn to review the literature about the method of studying IT product user switching behavior. Based on the PPM framework of migration theory, we have developed a model around push, pull, and mooring effects to explore the influencing factors on users switching behavior in online learning platforms.

PPM theory is the leading paradigm of population migration research [21]. Migration refers to the movement of humans between two places for a certain period and is produced by the comprehensive influence of the push force of emigration and the pull force of emigration [22]. Online user switching behavior and population migration have the same characteristics, that is, they move from one place to another, so PPM theory can better understand user switching behavior [23]. Many researchers have introduced related theories and concepts based on PPM framework, which were developed to explain human being's immigration behavior [24] and to explore IT switching behavior research [25].

By reviewing pertinent IS literature, some studies have also constructed distinct switching models. For instance, Cheng et al. [26] applied the PPM model to prove that three antecedents were influencing SNS user switching intention: push, pull, and anchor factors. Jung et al. [27] studied the user switching behavior of Korean Airlines and found that the factors in the PPM model affected traveler switching intention. Xia et al. [28] studied the influencing factors of music platform users switching behavior, based on PPM theory. Cheng et al. [10] studied the switching willingness of mobile cloud storage services in the Chinese market based on PPM. All these existing studies have enriched the application field of PPM theory. Therefore, we consider that the PPM framework is a suitable model for our study. In addition, this paper develops a model that examines the influencing factors of online learning user switching behavior based on PPM theory.

\section{Research Framework}

\subsection{Research Foundation}

The PPM framework suggests that migration is influenced by the PPM factors [29]. In the PPM framework, factors influencing user switching behavior can be categorized into push, pull, and mooring categories. Push factors refer to the negative factors driving people away from the original area, while pull factors are positive factors attracting people to a destination [30]. Mooring factors refer to all personal or social issues that act to facilitate or hamper migration decisions [29,31]. Push and pull factors can influence the switching behavior directly, while the mooring factors can moderate the effect of push and pull factors [13]. PPM theory has been widely used in the research of consumer behavior but is relatively scarce in the research on online learning context. Various factors have been summarized in the light of prior research about switching behavior in different research contexts $[10,13,15,26,32,33]$. Based on reviewing the relevant literature, this paper develops a research model based on the PPM theory to investigate the dynamic evolution process of user switching between platforms.

According to the segmentation result of the online learning market, the learning content can be divided into K12 (kindergarten through twelfth grade) education, higher education, language learning, vocational training, quality learning, and comprehensive online school. Higher education and vocational training, as the main body of the online education market, accounts for about $75 \%$ of the overall market. The online learning platform has its different characteristics in acquiring new users with other online IT products. Firstly, the decision-making period of users is long, which means it takes a long time for users to determine which platform to use; secondly, K12 education and quality education are multi-person decision programs, and the retention rate of experienced users is low. There must be some other critical factors that facilitate or hamper a user's switching choice. 
Therefore, we try to explore and investigate the promoting or resisting factors affecting the user switching behavior from its own unique features.

\subsection{Research Model}

Based on the above discussion, a research model in the online learning context was developed where the push effects, pull effect, and mooring effect were proposed to be the impetuses to switch the online learning platform, as shown in Figure 1.

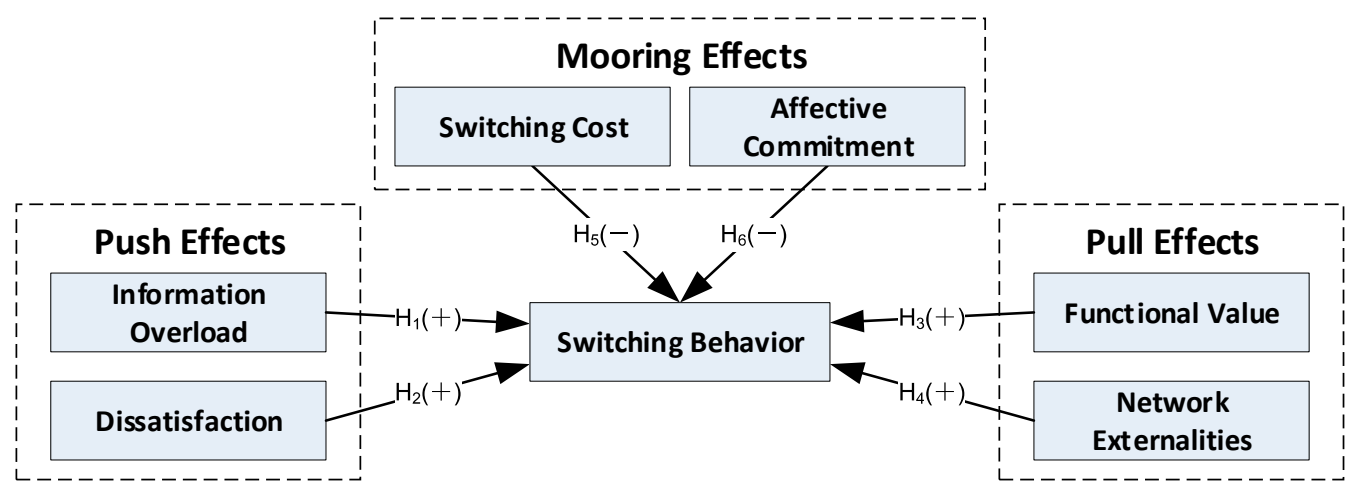

Figure 1. Research model of user switching behavior in online learning platforms.

\subsubsection{Push Effects}

Push factors mainly include two aspects; information overload in the learning platform and customer dissatisfaction.

Overload is a core factor that results in negative consequences. Information overload occurs when people are exposed to more information than they can accommodate in their capacity for the information process [34]. In the use of the platform, users need to focus on the learning of courses and resources. If the amount of information is too large, redundant information will reduce the learning efficiency of users. When the platform information exceeds the processing capacity, users may have negative emotions such as burnout and pressure [34,35]. Zhang et al. [36] divided perception overload into system function overload, information overload, and social overload, and verified that three types of overloads affect user's continuous use behavior. Zhu et al. [37] believed that perceived information overload has a significant negative impact on the willingness to continue using the government's new media platform. Similarly, social media information overload will lead to the decline of user attention, reduce the efficiency of user information processing, and lead to the loss of social media users.

As a core concept in service post-adoption research, satisfaction is defined as the summary psychological state resulting when the emotion surrounding disconfirmed expectation is coupled with the consumer's prior feelings about the consumption experience [15]. In the study of human migration behavior, satisfaction is also the main reason for residents to leave the original area. More precisely, in the online learning platform, customer satisfaction reflects the degree of a customer's positive evaluation of the learning platform and experience with this platform. In the existing literature, many scholars have found that users' dissatisfaction with the original service leads to switching behavior. For example, $\mathrm{Xu}$ [38] found that users' dissatisfaction with social platforms has a positive impact on user switching behavior. Chen et al. [39] also found that there is a significant positive impact between dissatisfaction and user exit intention. Satisfaction is the pre-motivation of whether users continue to use and switching behavior, and improving satisfaction has a significant impact on continuous use behavior [40]. When users are satisfied with the original system, the switching intention is weak.

Therefore, this study takes information overload and dissatisfaction as the factors to promote user switching behavior. As such, in the current study, we suppose that user's 
dissatisfaction with the incumbent provider is the push factor that influences user switching intention. Therefore, the following hypothesis is proposed:

Hypothesis 1. Information overload has a positive impact on user switching behavior.

Hypothesis 2. User dissatisfaction has a positive impact on user switching behavior.

\subsubsection{Pull Effects}

According to the PPM theory, the attractiveness of the destination will pull the migrants to this place [15]. Attractiveness is defined as the positive characteristics of an alternative service provider. Following [41], the attractiveness of alternatives means the service quality, image, and reputation of the replacing services' providers, which are expected to offer more suitable or superior services than those of the current provider. Several studies $[15,26,32,33]$ have recognized the importance of the attractiveness of alternatives. As for online learning providers, functional value is the main factor of consumer's decision making, reflecting consumers' rational evaluation of products. Online learning platforms provide many complex elements, such as learning resources and activities, instructor's quality, and facilities, and these must be well developed and designed for users to improve their skills and competitiveness [42]. In the competition of similar platforms, if the alternative platform provides better learning resources and modes, users may reduce or stop using the incumbent platform. Fang et al. [4] studied the switching behavior of traditional education platforms to $5 \mathrm{G}$ platforms and found that users would consider whether the online platform has artificial intelligence, Internet of things, and other functions or not. The competing platform would offer comprehensive functions to induce the switching behavior. However, when customers were unaware of the alternatives more attractive than their current platform, they were likely to continue using the current provider. Accordingly, the following hypothesis is formulated:

Hypothesis 3. Functional value has a positive impact on the user switching behavior.

In addition to its functionality, network externality is also one of the pull factors inducing users' willingness to switch to an alternative, especially under the online environment. Network externality means the increased utility that users obtain from using products and services [43]. The network effect for a user would increase as the number of users on the same platform increases [44]. In our study, the network included peers, friends, colleagues, or others in their social circles who adopt the same learning platform. Users need to share and communicate with more peers; therefore, the network effect is a critical factor for studying online learning platforms. With the increase of platform users, externalities benefit emerges and attracts more users. Other users tend to choose the learning platform with more friends after comparing the price gap, communication convenience, and other factors. It is evident that network externality is an important pulling factor for IT products in many research contexts, such as the study of Cheng et al. (2019) [10] (mobile personal cloud store), Xia et al. [28] (music platform), and Hou [32] (social network sites).

Therefore, the following hypothesis is proposed:

Hypothesis 4. Positive network externality has a positive impact on the user switching behavior.

\subsubsection{Mooring Effects}

Exiting research on mooring effects has primarily focused on cognitive-based factors such as switching cost [10]. The factor of affective components may also need to be considered. For this paper, we adopt switching costs and affective commitment as mooring factors.

Switching costs could be defined as the costs incurred when changing one provider to another one [45] or refer to user perceptions of the costs related to changing service providers, and it is throughout the whole switch process [15]. In many studies, switching cost is considered as the mooring effects influencing user switching behavior $[10,13,15,45-47]$. 
Users need to compare the switching cost and the benefits after the switch when making the switch decision. The switching cost includes the time, money, and effort paid in the usage of the current platform [13] and the additional money, time, and effort to explore and adopt new resources [48]. If users are sensitive to switching costs, this sensitivity makes users less willing to change and maintain the original state. Even though some customers may feel dissatisfaction with the current platform, they would not switch platforms since they may face a greater switch cost and risk of switching to a new service provider. It is because of the existence of switching costs that users can choose to continue to use the initial service or product. Therefore, from the exit barriers, which is an important factor for long-term retention of users.

Therefore, the following hypothesis is proposed:

Hypothesis 5. User switching costs of the incumbent provider has a negative effect on switching intention.

Commitment is defined as an individual's attachment to a particular target, which results in an inclination to maintain a relationship [49]. Affective commitment refers to an emotional attachment to identification with and involvement in the target and reflects a desire to stay in the relationship. Plenty of studies $[15,50,51]$ adopt this core indicator to grasp the affective component in consumer behavior and demonstrate that affective commitment facilitates users to maintain the relationships with the incumbent service because of their emotional bond to the service. In the context of online learning, affective commitment is identified as a crucial factor affecting the online learning continuance intention. Online learning users often interact with platform experts and teachers and establish positive emotions with the incumbent platform, which may lead to users' high level of involvement in the platform [52]. Without a strong sense of affective commitment to the incumbent platform, the users may easily switch to another alternative [51]. Therefore, the following hypothesis is proposed:

Hypothesis 6. User's affective commitment to the incumbent platform has a negative impact on the switching behavior.

\section{Research Design}

\subsection{Measurement}

There were seven constructs of interest to this study, including information overload, dissatisfaction with the incumbent, alternative attractiveness, network externality, switching cost, emotional commitment, and switching behavior.

All the items were measured by 5-point Likert scales range from "strongly disagree" to "strongly agree". Table 1 lists the measurement scale used in this study. The related literatures are also listed in Table 1.

Table 1. Constructs and measures.

\begin{tabular}{|c|c|c|}
\hline Constructs & Items & Measures \\
\hline \multirow{4}{*}{ Information overload $[34-37,53]$} & IO1 & I feel overwhelmed with the large volume of information everyday. \\
\hline & $\mathrm{IO} 2$ & Only a small part of the information is what I need. \\
\hline & $\mathrm{IO} 3$ & It is less efficient way of obtaining effective course information. \\
\hline & $\mathrm{IO} 4$ & I am frequently disturbed by push information \\
\hline \multirow{5}{*}{$\begin{array}{l}\text { Dissatisfaction with tncumbent } \\
\text { platform }[15,38-40,54,55]\end{array}$} & DS1 & Dissatisfied with the quality of teachers and course on the platform. \\
\hline & DS2 & Dissatisfied with the speed and depth of the platform's response to \\
\hline & DS3 & $\begin{array}{l}\text { Dissatisfied with the platform's fees, refunds, and other financial } \\
\text { protection issues }\end{array}$ \\
\hline & DS4 & Dissatisfied with the level of protection in personal privacy. \\
\hline & DS5 & $\begin{array}{l}\text { Dissatisfied with the inability of timely feedback when using the platform's } \\
\text { recording format. }\end{array}$ \\
\hline
\end{tabular}


Table 1. Cont.

\begin{tabular}{|c|c|c|}
\hline Constructs & Items & Measures \\
\hline \multirow{5}{*}{ Functional value $[4,42,56]$} & FC1 & $\begin{array}{l}\text { I think the learning mode of another platform can bring better value to } \\
\text { the capital }\end{array}$ \\
\hline & FC2 & $\begin{array}{l}\text { I think the learning mode of another platform is more scientific, and the scene is } \\
\text { more vivid than the incumbent platform. }\end{array}$ \\
\hline & FC3 & $\begin{array}{l}\text { I think the learning resources of another platform are more abundant and } \\
\text { high quality. }\end{array}$ \\
\hline & FC4 & $\begin{array}{l}\text { I think another platform will provide personalized services to better meet } \\
\text { individual needs. }\end{array}$ \\
\hline & FC5 & $\begin{array}{l}\text { I think the teaching explanation is more closely integrated with technology in } \\
\text { another platform. }\end{array}$ \\
\hline \multirow{3}{*}{$\begin{array}{c}\text { Network } \\
\text { externality }[10,28,32,43,44,57]\end{array}$} & NE1 & Many of my friends are using another platform \\
\hline & NE2 & My respected teachers and friends recommend another platform \\
\hline & NE3 & I anticipate many people will use another platform. \\
\hline \multirow{4}{*}{ Switching cost $[10,13,15,45-47]$} & SC1 & $\begin{array}{l}\text { In general, it would spend a lot of money, time, and effort to switch to a } \\
\text { new platform. }\end{array}$ \\
\hline & SC2 & $\begin{array}{l}\text { I would lose the accumulated credit and service in the current platform if I were } \\
\text { to switch to a new platform. }\end{array}$ \\
\hline & SC3 & $\begin{array}{l}\text { I would lose the benefits of being a long-term user of the current platform if I } \\
\text { were to switch to a new platform. }\end{array}$ \\
\hline & SC4 & $\begin{array}{l}\text { It would take a lot of time and effort to evaluate the learning resources and } \\
\text { services of the new platform. }\end{array}$ \\
\hline \multirow{4}{*}{ Affective commitment $[15,50,51,58]$} & AC1 & I value some teachers and courses on the current platform \\
\hline & AC2 & I like to communicate with teachers and other users on the current platform \\
\hline & AC3 & I really like the public image of the current platform. \\
\hline & AC4 & I feel emotionally attached to my current platform. \\
\hline \multirow{4}{*}{ Switching behavior } & SB1 & I would spend less time on my incumbent platform. \\
\hline & SB2 & I am considering stopping using my incumbent platform. \\
\hline & SB3 & I am considering switching from my incumbent platform to another. \\
\hline & SB4 & $\begin{array}{l}\text { I am determined to switch to another platform, and I am already trying to use } \\
\text { another platform. }\end{array}$ \\
\hline
\end{tabular}

\subsection{Data Collection}

To test the research model, an online survey of online education users was conducted. The questionnaire was surveyed and collected in a university in Henan, China. Then the students shared the questionnaire with their friends and families. A total of 313 valid samples were collected.

The demographic characteristics of the final sample are shown in Table 2. Among these valid responders, males accounted for $44.7 \%$ and females for $55.3 \%$. In total, $57.8 \%$ of responders were between the ages of 18 to 25 , which is consistent with young people's strong learning needs and active engagement on the Internet. For education background demographics, most of the respondents had an undergraduate degree or higher.

The use of online learning platforms is shown in Table 3. From the survey results, we found that over half of the sample users had used two or more online learning platforms, indicating that they would switch one platform to another one easily. The proportion of people who use language learning platforms was the highest, followed by higher education platforms and vocational training platforms. It reflects the characteristics of online education platform users' high education level, as well as the demand for professional and effective information and resources, which is in line with the educational level of the sample population. 
Table 2. Demographic statistics.

\begin{tabular}{|c|c|c|c|}
\hline Survey Object & Options & Quantity & Percentage \\
\hline \multirow{2}{*}{ Gender } & Male & 140 & $44.7 \%$ \\
\hline & Female & 173 & $55.3 \%$ \\
\hline \multirow{5}{*}{ Age } & Under 18 & 61 & $19.5 \%$ \\
\hline & $18-25$ & 181 & $57.8 \%$ \\
\hline & $26-40$ & 64 & $20.4 \%$ \\
\hline & Above 40 years old & 7 & $2.3 \%$ \\
\hline & Postgraduate and above & 52 & $16.6 \%$ \\
\hline \multirow{3}{*}{ Education } & Undergraduate & 170 & $54.3 \%$ \\
\hline & Specialist & 15 & $4.8 \%$ \\
\hline & High school and below & 76 & $24.3 \%$ \\
\hline Monthly income & Below 1000 yuan & 102 & $32.6 \%$ \\
\hline \multirow[t]{4}{*}{ (including student allowance) } & $1001-3000$ yuan & 90 & $28.7 \%$ \\
\hline & $3001-5000$ yuan & 66 & $21.0 \%$ \\
\hline & 5001-8000 yuan & 32 & $10.2 \%$ \\
\hline & 8001 yuan and above & 23 & $7.5 \%$ \\
\hline
\end{tabular}

Table 3. Analysis of online learning platforms.

\begin{tabular}{|c|c|c|c|}
\hline Survey Object & Options & Quantity & Percentage \\
\hline \multirow{6}{*}{$\begin{array}{l}\text { The use situation of online } \\
\text { learning platforms }\end{array}$} & $\begin{array}{l}\text { K12 education platform (such as homework help, Xueersi } \\
\text { online school, ape tutoring, etc.) }\end{array}$ & 69 & $22.0 \%$ \\
\hline & $\begin{array}{l}\text { Higher education platforms (such as Chinese University } \\
\text { MOOC, Postgraduate Entrance Examination Gang, TED etc.) }\end{array}$ & 226 & $72.2 \%$ \\
\hline & $\begin{array}{c}\text { Language learning platforms (such as Liulishuo, Netease } \\
\text { Youdao Dictionary, Momoback words, etc.) }\end{array}$ & 231 & $73.8 \%$ \\
\hline & $\begin{array}{l}\text { Vocational training platforms (such as Zhong Gong Education, } \\
\text { Driving Test Baodian, China Accounting Online School, etc.) }\end{array}$ & 140 & $44.7 \%$ \\
\hline & $\begin{array}{l}\text { Comprehensive online school platforms (such as NetEase Open } \\
\text { Class, Tencent Class, New Oriental Online, etc.) }\end{array}$ & 102 & $32.6 \%$ \\
\hline & $\begin{array}{l}\text { Quality education platforms (such as Squirrel AI, Programming } \\
\text { Cat, etc.) }\end{array}$ & 34 & $10.9 \%$ \\
\hline
\end{tabular}

\section{Result and Discussion}

Structure equation modeling has two common methods, covariance-based SEM (CBSEM) and partial least square SEM (PLS-SEM). This study adopts the CB-SEM due to two considerations.

The first is about the research model-since CB-SEM is a confirmatory approach, the method requires the specification of the full theoretical model prior to data analysis. Further, it is more appropriate for established theory testing and confirmation [59]. In contrast, PLS-SEM is suitable for early-stage theory development and testing [60,61] and is used to explore the constructs and relationships in complex structural models. The model in our study has a sound theoretical foundation (PPM theory), and the direction of the relationship between variables (the influencing factors of users switching behavior in online learning platform) is determined, therefore, CB-SEM should be suitable for this study.

The second is about the research sample size. PLS-SEM works efficiently with small samples and does not need assumptions about distribution. In contrast, CB-SEM requires large samples than PLS-SEM, but CB-SEM has lower variability than PLS-SEM in the case of large sample size. The sample volume in our study is over 300 , which is rather larger as fit in the requirement of CB-SEM.

There are two stages during data analysis: (1) measurement modeling for the reliability and validity of the measurement scale, and (2) structural modeling for hypothesis testing. 


\subsection{Measurement Model}

The goal of measurement modeling was to assess the reliability and validity of the measurement scales. The reliability of the measurements was examined using composite reliability (CR) and Cronbach's Alpha. The critical values for CR and Cronbach's Alpha are 0.7 and 0.7 , respectively. Table 4 shows the results of CR and Cronbach's Alpha were all higher than the recommended value, indicating that all the constructs were reliable.

Table 4. Reliability and validity.

\begin{tabular}{|c|c|c|c|c|c|}
\hline Constructs & Items & Loading & Cronbach's $\alpha$ & CR & AVE \\
\hline & IO1 & 0.772 & \multirow{6}{*}{0.841} & \multirow{6}{*}{0.842} & \multirow{6}{*}{0.571} \\
\hline \multirow{5}{*}{ Information Overload } & IO2 & 0.782 & & & \\
\hline & IO3 & 0.758 & & & \\
\hline & $\mathrm{IO} 4$ & 0.709 & & & \\
\hline & DS1 & 0.767 & & & \\
\hline & DS2 & 0.881 & & & \\
\hline \multirow[t]{4}{*}{ Dissatisfaction } & DS3 & 0.835 & \multirow[t]{4}{*}{0.913} & \multirow[t]{4}{*}{0.914} & \multirow[t]{4}{*}{0.679} \\
\hline & DS4 & 0.811 & & & \\
\hline & DS5 & 0.822 & & & \\
\hline & FV1 & 0.774 & & & \\
\hline \multirow{5}{*}{ Functional Value } & FV2 & 0.740 & \multirow{5}{*}{0.911} & \multirow{5}{*}{0.913} & \multirow{5}{*}{0.679} \\
\hline & FV3 & 0.850 & & & \\
\hline & FV4 & 0.836 & & & \\
\hline & FV5 & 0.909 & & & \\
\hline & NE1 & 0.855 & & & \\
\hline \multirow[t]{3}{*}{ Network Externality } & NE2 & 0.849 & \multirow[t]{3}{*}{0.878} & \multirow[t]{3}{*}{0.878} & \multirow[t]{3}{*}{0.706} \\
\hline & NE3 & 0.817 & & & \\
\hline & SC1 & 0.872 & & & \\
\hline \multirow{4}{*}{ Switching Cost } & SC2 & 0.901 & \multirow{4}{*}{0.932} & \multirow{4}{*}{0.935} & \multirow{4}{*}{0.782} \\
\hline & SC3 & 0.884 & & & \\
\hline & SC4 & 0.879 & & & \\
\hline & $\mathrm{AC} 1$ & 0.887 & & & \\
\hline \multirow{4}{*}{ Affective Commitment } & AC2 & 0.835 & \multirow{4}{*}{0.921} & \multirow{4}{*}{0.922} & \multirow{4}{*}{0.747} \\
\hline & AC3 & 0.866 & & & \\
\hline & AC4 & 0.868 & & & \\
\hline & SB1 & 0.862 & & & \\
\hline \multirow{3}{*}{ Switching Behavior } & SB2 & 0.827 & \multirow{3}{*}{0.910} & \multirow{3}{*}{0.911} & \multirow{3}{*}{0.719} \\
\hline & SB3 & 0.900 & & & \\
\hline & SB4 & 0.800 & & & \\
\hline
\end{tabular}

Then, confirmatory factor analysis was used to test the convergent validity and discriminant validity. Convergence validity reflects the correlation degree of the same latent variable, while discriminant validity reflects the difference between different latent variables. The convergent validity of the constructs was examined by average variance extracted (AVE) and item loading significance. The recommended value of AVE is 0.5, and the minimum value of AVE in Table 4 is 0.571 . Meanwhile, as shown in Table 4 , all item loading were over 0.7 , suggesting satisfactory convergent validity.

Discriminant validity can be assessed by correlation matric and square roots of AVE for all constructs. Good discriminant validity requires that the square root of the AVE of each construct should be higher than the correlation of the specific construct with all the other constructs in the model. Table 5 shows that the square root of AVE value of each construct is higher than the correlation between two other factors, indicating that the measurement model has good discrimination validity. 
Table 5. Correlation matrix and square roots of AVE results of the tests.

\begin{tabular}{cccccccc}
\hline & IO & DS & FV & NE & SC & AC & SB \\
\hline IO & $\mathbf{0 . 7 5 6}$ & & & & & & \\
DS & 0.431 & $\mathbf{0 . 8 2 4}$ & & & & & \\
FV & 0.503 & 0.527 & $\mathbf{0 . 8 2 4}$ & & & & \\
NE & 0.585 & 0.504 & 0.467 & $\mathbf{0 . 8 4 1}$ & & & \\
SC & -0.402 & -0.259 & -0.312 & -0.363 & $\mathbf{0 . 8 8 4}$ & & \\
AC & -0.305 & -0.241 & -0.273 & -0.291 & 0.386 & $\mathbf{0 . 8 6 4}$ & \\
SB & 0.536 & 0.533 & 0.536 & 0.547 & -0.475 & -0.440 & $\mathbf{0 . 8 4 8}$ \\
\hline
\end{tabular}

Note: The bold numbers in the diagonal row represent the square roots of the AVE, and the off-diagonal values represent the correlations of each construct with other constructs.

\subsection{Structural Model}

The second step is to examine the significances and strengths of each hypothesis and the variable explained to the dependent variable. This part applies to adopt AMOS software and structural equation model (SEM) to carry out the empirical examination of the hypothesis. First, the model's goodness of fit and overall explanatory power was considered. Goodness-of-fit analysis refers to how well a model fits a set of observations [2]. The fitting hypothesis model in this study was evaluated according to the regular fitting indexes provided by AMOS software, shown in Table 6 . All meet the recommended values for the indexes [2].

Table 6. Goodness of fit test.

\begin{tabular}{ccc}
\hline Fitting Index & Recommended Value & Fitting Result \\
\hline CMIN $\backslash$ DF & $<3.0$ & 1.356 \\
GFI & $>0.9$ & 0.907 \\
AGFI & $>0.8$ & 0.887 \\
CFI & $>0.9$ & 0.981 \\
NFI & $>0.9$ & 0.932 \\
RFI & $>0.9$ & 0.922 \\
IFI & $>0.9$ & 0.981 \\
TLI & $>0.9$ & 0.978 \\
RMSEA & $<0.08$ & 0.034 \\
\hline
\end{tabular}

Figure 2 presents the results of the structural model. All the hypotheses have expected effects on switching intension at different significances, as seen in Table 7.

Table 7. Result of test.

\begin{tabular}{cccccc}
\hline Hypothesis & $\begin{array}{c}\text { Path } \\
\text { Coefficient }\end{array}$ & S.E. & C.R. & P & Result \\
\hline $\mathrm{SB} \leftarrow \mathrm{IO}$ & 0.158 & 0.068 & 2.142 & 0.032 & Positive \\
$\mathrm{SB} \leftarrow \mathrm{DS}$ & 0.227 & 0.055 & 3.834 & $* * *$ & Positive \\
$\mathrm{SB} \leftarrow \mathrm{FV}$ & 0.176 & 0.059 & 2.952 & 0.003 & Positive \\
$\mathrm{SB} \leftarrow \mathrm{NE}$ & 0.155 & 0.077 & 2.2 & 0.028 & Positive \\
$\mathrm{SB} \leftarrow \mathrm{SC}$ & -0.184 & 0.043 & -3.596 & $* * *$ & Negative \\
$\mathrm{SB} \leftarrow \mathrm{AC}$ & -0.174 & 0.044 & -3.58 & $* * *$ & Negative \\
\hline Note: ${ }^{* * *} p<0.001$. & & & & &
\end{tabular}

As expected, dissatisfaction with the incumbent platform has significantly positive effects on switching intention, validating hypothesis 2 . It shows that satisfaction is the primary factor of user continuous use behavior. The conclusion is further verified in the online education field. Users will prefer to switch to a more satisfying platform when they are dissatisfied with the incumbent one. Information overloading $(\beta=0.158, p=0.032)$, another one of push factors also has a positive but a weak significance effect on switching intention positively. This conclusion can support hypothesis 2 . Information overload 
will reduce the user's immersion in the learning process and affect the learning effect. However, it has less impact on user switching behavior compared with dissatisfactory with incumbent one.

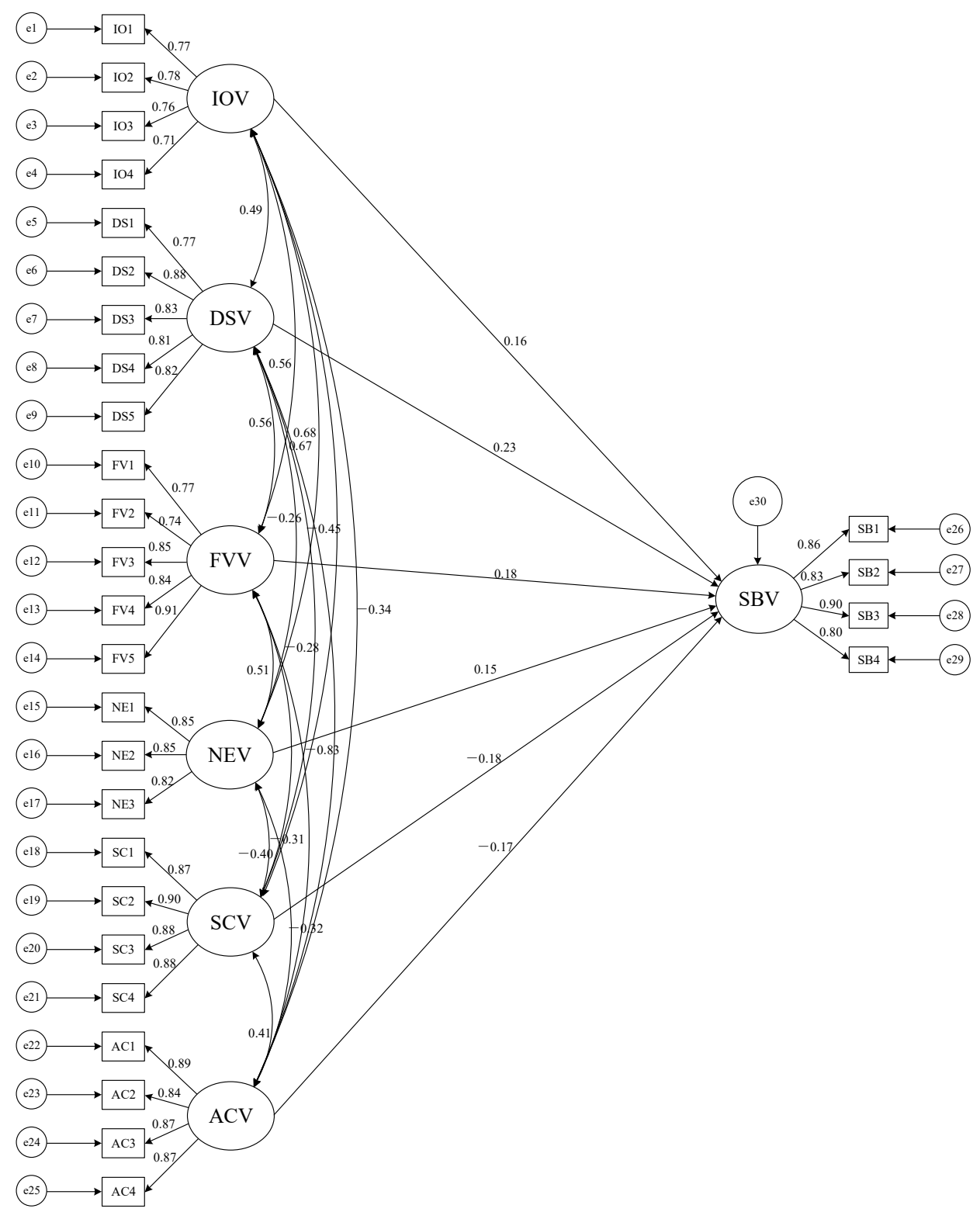

Figure 2. SEM model analysis. Note: $\mathrm{IO}=$ information overload; $\mathrm{DS}=$ dissatisfaction; $\mathrm{FV}=$ functional value; $\mathrm{NE}=$ network externality; $\mathrm{SC}=$ switching cost; $\mathrm{AC}=$ affective commitment; $\mathrm{SB}=$ switching behavior.

For pull factors, alternative attractiveness $(\beta=0.176, p=0.003)$ and network externality ( $\beta=0.155, p=0.028)$, positively affect the switching behavior, indicating that users not only pay attention to the functional value of the alternative platform, but also are affected by personal emotional needs. When the learning resources and teachers' team of the alternative platform are better, the switching behavior is more likely to occur. In other words, the learning resources provided by the current platform cannot meet the users' needs to upgrade, leading users to turn to other platforms. Secondly, users have an emotional connection with other friends through the use of a learning platform. Social networks will convey more information about the alternative platforms by friends around them, thus affecting user switching behavior. This conclusion also confirms the importance of word-of-mouth and promotion. Among the two factors, the significance of functional value is stronger. In this respect, functional value is more important to customers. 
On the contrary, for the mooring factors, the switching cost and emotional commitment are found to have significantly negative effects on switching intention, supporting the hypothesis that two mooring factors influence switching intention greatly. The possible reason is that users worry about the uncertain cost in the process of service switching, which not only exists in the search and evaluation cost, but also in the process of learning and understanding effort to adopting a new platform. In addition, the original platform often provides exclusive benefits such as student benefits and points for retained customers, which makes users sensitive in the conversion process and inhibits the occurrence of user switching behavior. In conclusion, the keen emotional commitment to the incumbent platform and perception of high switching costs would make users continue to use the incumbent platform.

Based on the above, users are affected by the interaction of pull, push, and mooring factors in the process of switching. Users of online learning platforms would make the optimal decision after considering all these three factors.

\subsection{Expansibility Analysis}

The effect of the three factors discussed above on user switching behavior also depends on the type of online learning platform. This study will further analyze the different influence factors and mechanisms of switching behavior for different types of platforms. According to the survey, we know that higher education platforms and language learning platforms have a larger market scale. Therefore, this paper compares the different influence factors for user switching behavior between the two platforms. The test results are shown in Table 8. Model 1 describes the user switching behavior of higher education platforms, and model 2 is for language learning platforms.

Table 8. Result of tests.

\begin{tabular}{|c|c|c|c|}
\hline & Expansion Variables & Model 1 & Model 2 \\
\hline \multirow{6}{*}{ Independent variable } & Information overload & 0.74 & $0.190^{* *}$ \\
\hline & Dissatisfactory & $0.172 * *$ & $0.213^{* * *}$ \\
\hline & Function value & $0.175^{* *}$ & $0.140 *$ \\
\hline & Network externality & $0.210^{* *}$ & $0.167^{*}$ \\
\hline & Switching cost & $-0.219^{* * *}$ & $-1.77^{* *}$ \\
\hline & Affective commitment & $-0.170^{* *}$ & $-1.56^{* *}$ \\
\hline \multirow{3}{*}{ Regression indicators } & $\mathrm{R}^{2}$ & 0.715 & 0.745 \\
\hline & $\operatorname{Adj} R^{2}$ & 0.498 & 0.543 \\
\hline & $\mathrm{F}$ & 38.184 & 46.479 \\
\hline
\end{tabular}

In model 1, except for information overload, other factors have a significant effect on the user switching behavior, just as expected. The results show that these factors have the same effect on the users of higher education platforms as with other platform types. However, the item of information overload cannot support the hypothesis, indicating that this item has less effect on the switching intention. The possible reason is that the users of higher education learning need much information and become less sensitive to a large amount of information supply-among them, the switching cost has the greatest influence on such users. The curriculum content of the higher education platform is more professional and coherent, and users pay special attention to the process and results. The switching behavior not only makes users lose sunk costs, but also need to pay new costs to find curriculum resources. The network externality has the second greater influence. Due to the curriculum design and teachers, the decision-making cycle of higher education users is longer and the process is more complex. They are more influenced by the recommendation of teachers and friends. Therefore, the network externality in the higher education platform model has a stronger effect on user switching behavior.

For model 2, all these push, pull, and mooring factors can also have the expected effect on the switching behavior. Among them, dissatisfaction with the incumbent platform has 
the greatest influence on the switching intention. Language learning platforms provide users with listening, speaking, reading, writing, translation, and other functions, and users' continuous use depends on whether these functions can meet their needs. Different from higher education platforms, language learning platforms are not a must for most users, and product homogeneity is significant. If users are not satisfied with a certain platform, it is easy for them to switch to other learning platforms.

\section{Conclusions}

Online learning platforms provide richer resources and diminish the barrier of time and space of traditional teaching mode [62]. Therefore, it is important to ensure that sustainable development and performance enhancement for the online learning platform.

This study attempted to conduct a thorough analysis of influencing factors on user switching behavior to avoid the loss of existing users and effectively retain current users for online platforms, thus maintaining the sustainable development in these platforms. Based on PPM theory, the mechanism of user switching behavior is examined on online learning platforms. First, the results of the empirical study confirm the role of the factors in the hypotheses in shaping learning platform switching intention. Second, among these factors, the dissatisfaction of online learning users has the greatest impact on switching intention, which is consistent with the online learning study of Qian [20]. Moreover, the result also reflects the previous research on immigration theory $[24,63]$. The mooring factors-switching cost and affective commitment-have a significantly negative impact on switching intention, which is in line with the switching behavior study of Sun [15] and the study of Dong [64]. Third, our study further analyzed the influencing factors for different types of online learning platforms. We found that there were significant differences in the impact of information overload on different types of platforms. For language learning platforms, the user's dissatisfaction is the greatest impact factor, while the network externality and switching cost are the vital influencing factors for high education platforms.

Online learning platforms play a vital role in providing suitable facilities for learners to acquire knowledge and skills and the chances for the learner to be a life-long learner. Fostering life-long learning is crucial not only for improving people's skills but also for the country. It aligns with the Agenda 2030, aiming to "ensure inclusive and equitable quality education and promote life-long learning opportunities for all". Therefore, it is crucial for maintaining the sustainable development of online platforms.

The findings in this study offer new insights and practical implications for the sustainable development of online learning platforms. "Online learning" is a complex multidimensional framework system. Promoting the efficient matching of demand and supply is the key to the sustainable development of online education. Therefore, online education needs to increase the functionality of platforms with the help of technology to improve customer satisfaction to strengthen emotional communication with customers through humanistic concerns and to seek sustainable development. To achieve this, they should aim to (1) Meet the diversified needs of users with the application of technology. Compared with the "sense of presence" of traditional classroom teaching, online learning platforms lack real-time interaction and a sense of experience. It is urgent to use artificial intelligence and virtual reality technology to improve the level of interaction in the process of teaching, thus improving the quality of teaching and increasing the attractiveness for users. In the process of online learning, a personalized learning scheme is provided to improve the learning efficiency and emotional experience of users, which can not only meet the individual needs in online learning, but also to enhance user satisfaction of online education services. (2) Strengthen the emotional identity of users with humanistic concerns. Online learning is not only a network of curriculum services but also a network of user-centered communities. It pays attention to the voice and demand of users, helps users to find peers and groups in learning, promotes the exchange between teachers and students, strengthens the communication between the platform and the user. The platform should strengthen the emotional connection with users on the basis of curriculum services and cultivate the 
user's sense of identity and belonging in the online learning platform, thus enhancing the user's "stickiness" to the service of online learning platforms.

Some limitations in this paper can be further improved in future studies. The dependent variable was constructed to measure the switching intention based on PPM theory. However, some important factors are not included in this model. Other variables should be considered in future studies that might impact the switching intention. In addition, the samples were restricted to younger adults. Data accounting for teenage and middle age users were not included in this study. If more data covering all age groups are available to conduct future studies on this subject, then better explanations should be drawn. Dependent variables like age and educational background should be considered carefully to obtain more findings.

Author Contributions: H.X. contributed to conceptualization, methodology, and supervision; J.W. contributed to the investigation, formal analysis, and writing and editing of the original draft; Z.T. contributed to validation and editing; H.-C.L. contributed to review. All authors have read and agreed to the published version of the manuscript.

Funding: This research received no external funding.

Institutional Review Board Statement: Not applicable.

Informed Consent Statement: Informed consent was obtained from all subjects involved in the study.

Data Availability Statement: Not applicable.

Conflicts of Interest: The authors declare no conflict of interest.

\section{References}

1. Chen, J.; Liu, C.; Chang, R.; Gui, P.; Na, S. From Traditional to VR-Based Online Education Platforms: A Model of the Mechanism Influencing User Migration. Information 2020, 11, 423. [CrossRef]

2. Li, Y.W.; Nishimura, N.; Yagami, H.; Park, H.S. An Empirical Study on Online Learners' Continuance Intentions in China. Sustainability 2021, 13, 889. [CrossRef]

3. Oraif, I.; Elyas, T. The Impact of COVID-19 on Learning: Investigating EFL Learners' Engagement in Online Courses in Saudi Arabia. Educ. Sci. 2021, 11, 99. [CrossRef]

4. Fang, J.M.; Shi, Z.H.; Liu, L. The influence mechanism of learner migration behavior in online education platform based on 5G technology. Mod. Distance Educ. Res. 2019, 31, 22-31.

5. Hsieh, J.K.; Hsieh, Y.C.; Chiu, H.C.; Feng, Y.C. Post-adoption switching behavior for online service substitutes: A perspective of the push-pull-mooring framework. Comput. Hum. Behav. 2012, 28, 1912-1920. [CrossRef]

6. Nikbin, D.; Ismail, I.; Marimuthu, M. The impact of causal attributions on customer satisfaction and switching intention: Empirical evidence from the airline industry. J. Air Transp. Manag. 2012, 25, 37-39. [CrossRef]

7. Han, H.; Kim, W.; Hyun, S.S. Switching intention model development: Role of service performances, customer satisfaction, and switching barriers in the hotel industry. Int. J. Hosp. Manag. 2011, 30, 619-629. [CrossRef]

8. Liang, L.J.; Choi, H.C.; Joppe, M. Exploring the relationship between satisfaction, trust and switching intention, repurchase intention in the context of Airbnb. Int. J. Hosp. Manag. 2018, 69, 41-48. [CrossRef]

9. Zhao, Y.X.; Liu, Z.Y. User switch behavior in IT adoption and usage: A literature review. Libr. Inf. 2017, 5, 86-96.

10. Cheng, S.; Lee, S.J.; Choi, B. An empirical investigation of users' voluntary switching intention for mobile personal cloud storage services based on the push-pull-mooring framework. Comput. Hum. Behav. 2019, 92, 198-215. [CrossRef]

11. Bhattacherjee, A.; Limayem, M.; Cheung, C.M. User switching of information technology: A theoretical synthesis and empirical test. Inf. Manag. 2012, 49, 327-333. [CrossRef]

12. Ye, C.; Potter, R. The role of habit in post-adoption switching of personal information technologies: An empirical investigation. Commun. Assoc. Inf. Syst. 2011, 28, 585-610. [CrossRef]

13. Wu, K.W.; Vassileva, J.; Zhao, Y.X. Understanding users' intention to switch personal cloud storage services: Evidence from the Chinese market. Comput. Hum. Behav. 2017, 68, 300-314. [CrossRef]

14. Yao, X.; Phang, C.W.; Ling, H. Understanding the influences of trend and fatigue in individuals' SNS switching intentioned. In Proceedings of the 48th Hawaii International Conference on System Sciences (HICSS), Kauai, HI, USA, 5-8 January 2015; IEEE: Piscataway, NJ, USA, 2015; pp. 324-334.

15. Sun, Y.Q.; Liu, D.N.; Chen, S.J.; Wu, X.R.; Shen, X.L.; Zhang, X. I Understanding users' switching behavior of mobile instant messaging applications: An empirical study from the perspective of push-pull-mooring framework. Comput. Hum. Behav. 2017, 75, 727-738. [CrossRef] 
16. Choi, J.; Jung, J.; Lee, S.W. What causes users to switch from a local to a global social network site? The cultural, social, economic, and motivational factors of Facebook's globalization. Comput. Hum. Behav. 2013, 29, 2665-2673. [CrossRef]

17. Peng, X.; Zhao, Y.; Zhu, Q. Investigating user switching intention for mobile instant messaging application: Taking WeChat as an example. Comput. Hum. Behav. 2016, 64, 206-216. [CrossRef]

18. Park, S.C.; Ryoo, S.Y. An empirical investigation of end-users' switching toward cloud computing: A two factor theory perspective. Comput. Hum. Behav. 2013, 29, 160-170. [CrossRef]

19. Calvo-Porral, C.; Levy-Mangin, J.P. Switching behavior and customer satisfaction in mobile services: Analyzing virtual and traditional operators. Comput. Hum. Behav. 2015, 49, 532-540. [CrossRef]

20. Qian, Y. Research on the influencing factors of online learning users' continued use behavior-Based on the perspective of social network environment and academic positioning. Mod. Inf. 2015, 35, 50-56.

21. Bansal, H.S.; Taylor, S.F.; St. James, Y. "Migrating" to new service providers: Toward a unifying framework of consumers' switching behaviors. J. Acad. Mark. Sci. 2005, 33, 96-115. [CrossRef]

22. Kim, S.; Choi, M.J.; Choi, J.S. Empirical Study on the Factors Affecting Individuals' Switching Intention to Augmented/Virtual Reality Content Services Based on Push-Pull-Mooring Theory. Information 2020, 11, 25. [CrossRef]

23. Hou, A.C.; Chern, C.C.; Chen, H.G.; Chen, Y.C. 'Migrating to a new virtual world': Exploring MMORPG switching through human migration theory. Comput. Hum. Behav. 2011, 27, 1892-1903. [CrossRef]

24. Lee, E. A theory of migration. Demography 1966, 3, 47-57. [CrossRef]

25. Nimako, S.G.; Ntim, B.A. Construct specification and misspecification within the application of push-pull-mooring theory of switching behavior. J. Bus. Manag. Sci. 2013, 1, 83-95.

26. Chang, I.C.; Liu, C.C.; Chen, K. The push, pull and mooring effects in virtual migration for social networking sites. Inf. Syst. J. 2014, 24, 323-346. [CrossRef]

27. Jung, J.; Han, H.; Oh, M. Travelers' switching behavior in the airline industry from the perspective of the push-pull-mooring framework. Tour. Manag. 2017, 59, 139-153. [CrossRef]

28. Xia, L.X.; Wang, K.L.; Cheng, X.F. Research on user switching behavior of mobile music platform based on ppm model-Taking NetEase cloud music as an example. Mod. Inf. 2018, 38, 3-11.

29. Moon, B. Paradigms in migration research: Exploring "Moorings" as a schema. Prog. Hum. Geogr. 1995, 19, 504-524. [CrossRef]

30. Heberle, R. The causes of rural-urban migration: A survey of German theories. Am. J. Sociol. 1938, 43, 932-950. [CrossRef]

31. Ye, Q.; Zhou, R.; Anwar, M.A.; Siddiquei, A.N.; Asmi, F. Entrepreneurs and Environmental Sustainability in the Digital Era: Regional and Institutional Perspectives. Int. J. Environ. Res. Public Health 2020, 17, 1355. [CrossRef]

32. Hou, A.C.; Shang, R.; Huang, C.; Chuan, M.; Wu, K.; Shan, K. The effects of push-pull-mooring on the switching model for social network sites migration. In Proceedings of the 19th Pacific Asia Conference on Information Systems (PACIS), Chengdu, China, 24-28 June 2014.

33. Cheng, Z.Y.; Yang, Y.Y.; Lim, J. Cyber migration: An empirical investigation on factors that affect users' switch intentions in social networking sites. In Proceedings of the 42nd Hawaii International Conference on System Sciences, Waikoloa, HI, USA, 5-8 January 2009; IEEE: Piscataway, NJ, USA, 2009; pp. 1-11.

34. Lee, A.R.; Son, S.M.; Kim, K.K. Information and communication technology overload and social networking service fatigue: A stress perspective. Comput. Hum. Behav. 2016, 55, 51-61. [CrossRef]

35. Sasaki, Y.; Kawai, D.; Kitamura, S. Unfriend or ignore tweets: A time series analysis on Japanese Twitter users suffering from information overload. Comput. Hum. Behav. 2016, 64, 914-922. [CrossRef]

36. Zhang, S.; Zhao, L.; Lu, Y.; Yang, J. Do you get tired of socializing? An empirical explanation of discontinuous usage behavior in social network services. Inf. Manag. 2016, 53, 904-914. [CrossRef]

37. Zhu, H.C.; Li, J.; Hu, X.; Xiao, S.Y. Study on the influence of perceived integration and perceived overload on the willingness to continue using new media in public affairs. Mod. Intell. 2019, 39, 137-145.

38. Xu, Y.J.; Yang, Y.P.; Cheng, Z.Y.; Lim, J. Retaining and attracting users in social networking services: An empirical investigation of cyber migration. J. Strateg. Inf. Syst. 2014, 23, 239-253. [CrossRef]

39. Chen, J.; Deng, S.L. Research on the influencing factors of mobile digital reading app users' withdrawal willingness. Inf. Sci. 2017, $35,128-133$.

40. Lin, T.C.; Sheng, W.; Hsu, S.C.; Chou, Y.C. The integration of value-based adoption and expectation-confirmation models: An example of IPTV continuance intention. Decis. Support Syst. 2012, 54, 63-75. [CrossRef]

41. Kim, H.S.; Yoon, C.H. Determinants of subscriber churn and customer loyalty in the Korean mobile telephony market. Telecommun. Policy 2004, 28, 751-765. [CrossRef]

42. Al-Kumaim, N.H.; Alhazmi, A.K.; Mohammed, F.; Gazem, N.A.; Shabbir, M.S.; Fazea, Y. Exploring the Impact of the COVID-19 Pandemic on University Students' Learning Life: An Integrated Conceptual Motivational Model for Sustainable and Healthy Online Learning. Sustainability 2021, 13, 2546. [CrossRef]

43. Katz, M.L.; Shapiro, C. Network externalities, competition, and compatibility. Am. Econ. Rev. 1985, 75, $424-440$.

44. Hsu, C.L.; Lu, H.P. Why do people play on-line games? An extended TAM with social influences and flow experience. Inf. Manag. 2004, 41, 853-868. [CrossRef]

45. Calvo-Porral, C.; Faina-Medin, A.; Nieto-Mengotti, M. Satisfaction and switching intention in mobile services: Comparing lock-in and free contracts in the Spanish market. Telemat. Inform. 2016, 34, 717-729. [CrossRef] 
46. Burnham, T.A.; Frels, J.K.; Mahajan, V. Consumer switching costs: A typology, antecedents, and consequences. J. Acad. Mark. Sci. 2003, 31, 109. [CrossRef]

47. Bhattacherjee, A.; Park, S.C. Why end-users move to the cloud: A migration-theoretic analysis. Eur. J. Inf. Syst. 2014, 23, 357-372. [CrossRef]

48. Ashby, N.J.; Teodorescu, K. The effect of switching costs on choice-inertia and its consequences. PLoS ONE 2019, 14, 17-26. [CrossRef] [PubMed]

49. Fullerton, G. The impact of brand commitment on loyalty to retail service brands. Can. J. Adm. Sci. 2005, 22, 97-110. [CrossRef]

50. Bateman, P.J.; Gray, P.H.; Butler, B.S. The impact of community commitment on participation in online communities. Inf. Syst. Res. 2011, 22, 841-854. [CrossRef]

51. Hashim, K.F.; Tan, F.B. The mediating role of trust and commitment on members' continuous knowledge sharing intention: A commitment-trust theory perspective. Int. J. Inf. Manag. 2015, 35, 145-151. [CrossRef]

52. Brodie, R.J.; Ilic, A.; Juric, B.; Hollebeek, L. Consumer engagement in a virtual brand community: An exploratory analysis. Journal of business research. J. Bus. Res. 2013, 66, 105-114. [CrossRef]

53. Lee, K.C.; Kwon, S. Online shopping recommendation mechanism and its influence on consumer decisions and behaviors: A causal map approach. Expert Syst. Appl. 2008, 35, 1567-1574. [CrossRef]

54. Zhou, T. Examining user switch between mobile stores: A push-pull-mooring perspective. Inf. Resour. Manag. J. 2016, 29, 1-13. [CrossRef]

55. Bright, L.F.; Kleiser, S.B.; Grau, S.L. Too much Facebook? An exploratory examination of social media fatigue. Comput. Hum. Behav. 2015, 44, 148-155. [CrossRef]

56. Viswanath, V.; Michael, M.G.; Davis, G.B.; Davis, F.D. User acceptance of information technology: Toward a unified view. MIS Q. 2003, 27, 425-478.

57. Lin, C.P.; Bhattacherjee, A. Elucidating individual intention to use interactive information technologies: The role of network externalities. Int. J. Electron. Commer. 2008, 13, 85-108. [CrossRef]

58. Chiu, C.M.; Hsu, M.H.; Wang, E.T. Understanding knowledge sharing in virtual communities: An integration of social capital and social cognitive theories. Decis. Support Syst. 2006, 42, 1872-1888. [CrossRef]

59. Astr Ac Han, C.B.; Patel, V.K.; Wanzenried, G. A comparative study of CB-SEM and PLS-SEM for theory development in family firm research. J. Fam. Bus. Strategy 2014, 5, 116-128. [CrossRef]

60. Hair, J.F.; Hult, G.T.M.; Ringle, C.M.; Sarstedt, M. A Primer on Partial Least Squares Structural Equation Modeling (PLS-SEM); Sage: Thousand Oaks, CA, USA, 2014.

61. Ringle, C.; Sarstedt, M.; Hair, J.F. Partial least squares structural equation modeling: Rigorous applications, better results and higher acceptance. J. Long Range Plan. 2013, 46, 1-12.

62. Ahmad, N.; Quadri, N.N.; Qureshi, M.R.N.; Alam, M.M. Relationship Modeling of Critical Success Factors for Enhancing Sustainability and Performance in E-Learning. Sustainability 2018, 10, 4776. [CrossRef]

63. Bagozzi, R.P. Evaluating structural equation models with unobservable variables and measurement error: A Comment. J. Mark. Res. 1981, 18, 375-381. [CrossRef]

64. Dong, W.; Zhang, M.; Gao, C.L. Research on the influencing factors of learning effect of online education platform based on user experience. Distance Educ. China 2020, 11, 68-75. 